\title{
The Relationship of Serum Sex-Hormone Binding Protein and Free Androgen Index Levels to Newborn's Breast Enlargement
}

\author{
Avni Kaya ( $\square$ avnikaya@gmail.com ) \\ university https://orcid.org/0000-0002-8917-8037
}

Abdullah Erdil

Erzurum

\section{Zerrin Orbak}

erzurum

\section{Research Article}

Keywords: Newborn, Breast, Estrogen, Testosterone

Posted Date: January 28th, 2022

DOl: https://doi.org/10.21203/rs.3.rs-1255844/v1

License: (c) (1) This work is licensed under a Creative Commons Attribution 4.0 International License.

Read Full License 


\section{Abstract}

\section{Aim}

This study aimed to analyze body mass index, estrogen, testosterone, sex-hormone-binding-globulin (SHBG), free androgenic index (FAl), and estrogen/testosterone ratio and their relationship to breast enlargement in newborns. Additionally, we defined the mean, minimum, maximum, standard deviation, and percentiles of SHBG and FAI in 14-28 days-old babies.

\section{Methods}

Forty babies with breast enlargement aged 14-28 days ( 17 boys and 23 girls) were included in the study. As controls were taken 36 babies in the same age group ( 19 boys and 17 girls). The SHBG and FAl values were calculate as mean, minimum, maximum, standard deviation, and percentages in 14-28 days-old newborns. Normal values and 5th, 10th, 25th, 50th, 75th, 90th, and 95th percentiles of the SHBG and FAI values were calculated according to sex.

\section{Results}

The mean, standard deviation, minimum, and maximum SHBG values among girls, boys, and all participants were $74.84 \pm 26.21 \mathrm{ng} / \mathrm{dL}(26.80-135.20 \mathrm{ng} / \mathrm{dL}), 73.22 \pm 24.98 \mathrm{ng} / \mathrm{dL}(13.00-144.80 \mathrm{ng} / \mathrm{dL})$, and $74.07 \pm 25.48 \mathrm{ng} / \mathrm{dL}(13.00-144.80 \mathrm{ng} / \mathrm{dL})$, respectively. The mean, standard deviation, minimum, and maximum FAl values of girls, boys, and all participants were $0.44 \pm 0.33(0.03-1.38), 1.42 \pm 0.54(0.69-3.46)$, and $0.91 \pm 0.66(0.03-3.46)$, respectively.

\section{Conclusion}

Neonatal breast enlargement is not associated with weight, length, body mass index, estrogen, testosterone, SHBG, FAI, Estrogen/Testosterone ratio, or sex. In the physiology of neonatal breast enlargement, there are still situations that await clarification.

\section{What's Known}

The number of studies on the subject is very few about newborn breast enlargements. There are still situations that await clarification.

\section{What is New}

Our study has provided new information about newborn breast enlargements. 


\section{Introduction}

Physical breast development is named according to age and sex as telarche, gynecomastia, breast growth, breast enlargement, breast swelling, and breast hypertrophy. There is no proper medical terminology for physiological enlargement of breasts in the newborn. In this article, the term "breast enlargement" will be used. Breast enlargement does not occur in all newborns. Breast enlargement is seen in $65-90 \%$ of all newborns as a possible consequence of the continuing action of estrogens, progesterone, and mammotropic peptides that characterize the intrauterine environment. Breast enlargement usually resolves spontaneously a few weeks after birth, coinciding with the withdrawal of maternal hormones ${ }^{1}$. The breast tissue contains estrogen and androgen receptors. The estrogen-toandrogen balance is suggested to play an essential role in breast enlargement ${ }^{2}$. Mini-puberty in babies can cause an imbalance between estrogen and androgen concentrations ${ }^{3}$. Inequality in the serum concentrations or synthesis of androgen or estrogen can lead to gynecomastia or premature telarche 4 .

The Sex Hormone Binding Globulin (SHBG) plays a crucial biological role in regulating sex hormones. SHBG affects the function of some sex hormones, including testosterone and estrogen. Any change in SHBG level leads to an imbalance between estrogen and testosterone. Increased SHBG concentrations lead to lower free testosterone concentrations ${ }^{1,5}$. The SHBG binds androgens with higher affinity compared to estrogen 4 .

The free androgenic index (FAl) is calculated as [Total Testosterone $x 100 / \mathrm{SHGB}$. Normal FAl in children is $<5$. It is used in the diagnosis of hyperandrogenemic conditions such as hirsutism ${ }^{6}$.

This study aimed to analyze Body Mass Index (BMI), Estrogen, Testosterone, SHBG levels, FAl, and Estrogen/Testosterone ratio $(E / T)$ levels' influence in newborn breast enlargements. Additionally, we defined the mean, minimum, maximum, standard deviation, and percentiles of SHBG and FAI in 14-28 days-old babies.

\section{Methods}

This prospective study was performed to determine the weight, length, BMI, serum Estrogen, Testosterone, E/T ratio, SHBG, and FAl levels in babies presenting with breast enlargement to the Erzurum Atatürk University Faculty of Medicine Research Hospital Pediatric Endocrinology Clinic in Turkey. The study was approved by the university's ethical committee (Atatürk University, Faculty of Medicine, Ethical Committee. Session 7, Decision number: 62). Study purpose and methods were explained to all families, and their permissions were obtained.

Forty babies with breast enlargement aged 14-28 days ( 17 boys and 23 girls) were included in the study group, while 36 babies in the same age group (19 boys and 17 girls) were included in the control group. All babies were completely healthy except for breast enlargement. Babies were excluded if born between 38 and 42 weeks, had any congenital abnormality or chronic illnesses, and if a chronic disease was 
present in the mother. Breast enlargement was evaluated based on the highest breast diameter. The diameter was $>1 \mathrm{~cm}$ in all breast enlargement patients included in the study. Babies with the highest breast diameter of 0-1 cm were excluded. Cases with the highest breast diameter of $0 \mathrm{~cm}$ were included in the control group. Babies between 14-28 days old were specially selected to ensure standardization.

After acquiring informed consent, newborns' prenatal and postnatal histories were taken, and physical examinations were performed. Babies' age (day), height $(\mathrm{cm})$, body weight $(\mathrm{kg}), \mathrm{BMI}$, and breast enlargement stage were recorded. BMI was calculated by the weight $(\mathrm{kg})$ divided by the square of height $\left(\mathrm{m}^{2}\right)$. Patients were normal at physical examination apart from breast enlargement. Estradiol (male 0.1-32 $\mathrm{pg} / \mathrm{mL}$, female $0.05-50 \mathrm{pg} / \mathrm{mL}$ ), testosterone (total, males $0.075-4 \mathrm{ng} / \mathrm{mL}$, females $0.02-0.64 \mathrm{ng} / \mathrm{mL}$ ), SHBG (normal value: $13-144.8 \mathrm{ng} / \mathrm{dL}$ ), FAI (normal value: $0<5$ ) were measured from serum in blood specimens. FAl was calculated as: [Free Androgen Index = testosterone $(\mathrm{ng} / \mathrm{mL}) / \mathrm{SHBG}(\mathrm{ng} / \mathrm{mL}) \times 100$ ] . The serum samples were analyzed in the Atatürk University Health, Research, and Application Hosptital Biochemical Laboratory with the DXI800 hormone analyzer using the chemiluminescent method.

\section{STATISTICAL ANALYSIS}

The numerical data were expressed as mean, minimum, maximum, and standard deviation. Extreme values were removed. The SPSS 20 Program for Windows was used for the results. The One-Sample Kolmogorov-Smirnov test was used to determine whether numerical data in the breast enlargement and control groups were distributed normally. According to the One-Sample Kolmogorov-Smirnov test, the distribution of weight, height, BMI, testosterone, SHBG, and FAl levels of all participants were assessed to be normal. The Independent-sample T-test was used to make comparisons. According to the One-Sample Kolmogorov-Smirnov test, the distribution of estradiol and E/T levels was abnormal. The non-parametric alternative Mann-Whitney $U$ test was applied to compare these data. The SHBG and FAI values were calculated as mean, minimum, maximum, standard deviation, and percentages for 14-28 days-old newborns. The Pearson Chi-square test was used to determine whether there was a significant relationship between breast enlargement and sex. $\mathrm{P} \leq 0.05$ was considered significant.

\section{Results}

Forty newborns ( 23 girls $(57.5 \%)$ and 17 boys $(42.5 \%)$ ) were included in the study group. The study group's mean values were: age $20.30 \pm 3.86$ days (14-27 days), weight $3.96 \pm 0.44 \mathrm{~kg}(3.10-4.90 \mathrm{~kg})$, height $51.75 \pm 1.29 \mathrm{~cm}(49-55 \mathrm{~cm})$, and BMI $14.79 \pm 1.40$ (11.46-18.84). The study group's mean observed levels were: estrogen $11.30 \pm 8.22 \mathrm{pg} / \mathrm{mL}(1-31 \mathrm{pg} / \mathrm{mL})$, testosterone $0.56 \pm 0.39 \mathrm{ng} / \mathrm{mL}(0,04-1,29 \mathrm{ng} / \mathrm{mL}), \mathrm{SGBH}$ $73.19 \pm 27.10$ (13-135.2 ng/dL), FAl 0.93 \pm 0.77 (0.03-3.46), and E/T ratio 35.15 \pm 44.46 (0.77-225).

Thirty-six newborns (17 girls (47.2\%) and 19 boys (52.8\%)) were included in the study as the control group. The control group's mean values were: age $20.94 \pm 3.89$ days ( $14-29$ days), weight $3.83 \pm 0.45 \mathrm{~kg}$ (3.00-4.90 kg), height $51.33 \pm 1.92 \mathrm{~cm}(46-55 \mathrm{~cm})$, and BMI $14.55 \pm 1.60$ (11.09-18.38). The control group's mean mean observed blood parameters were: estrogen $11.80 \pm 7.42 \mathrm{pg} / \mathrm{mL}(1-32 \mathrm{pg} / \mathrm{mL})$, testosterone 
$0.62 \pm 0.38 \mathrm{ng} / \mathrm{mL}(0.12-1.41 \mathrm{ng} / \mathrm{mL})$, SGBH $75.05 \pm 23.88$ (26.80-144.8 ng/dL), FAI 0.88 \pm 0.51 (0.15-2.06), and $\mathrm{E} / \mathrm{T}$ ratio $26.78 \pm 21.99(1.11-91.4)$.

When our cases were evaluated according to breast enlargement, there were no significant differences in estrogen ( $p=0.696)$, testosterone ( $p=0.502)$, SGBG $(p=0.753)$, and FAI $(p=0.735)$ levels between the test and control group. There were no significant differences in chronological age $(p=0.472)$, weight $(p=0.197)$, height $(p=0.268)$, body mass index $(p=0.483), E / T$ ratio $(p=0.868)$, and blood variables between the study and control group. It was concluded that newborns' breast enlargement is independent of weight, length, body mass index, estrogen, testosterone, SHBG, FAl, and E/T ratio.

Our case's laboratory values were also evaluated according to sex. According to the independent-sample T-test, testosterone $(p<0.001)$ and FAI $(p<0.001)$ were significant regarding sex, but SHBG $(p=0.784)$ was not significant. According to the Mann-Whitney $U$ test, E/T ratio $(p<0.001)$ was significant concerning sex, but estradiol $(p=0.387)$ was not significant.

In the Pearson Chi-square test, no significant correlation was found between sex and breast enlargement $(p=0.370)$. While a significant relationship was found between sex and testosterone, FAl, and $E / T$, no significant relationship was found with estradiol. No significant relationship was found between sex and breast enlargement. It was concluded that newborn breast enlargement is independent of sex and estradiol.

SHBG was $74.84 \pm 26.21 \mathrm{ng} / \mathrm{dL}(26.80-135.20 \mathrm{ng} / \mathrm{dL})$ in girls and $73.22 \pm 24.98 \mathrm{ng} / \mathrm{dL}(13.00-144.80$ $\mathrm{ng} / \mathrm{dL})$ in boys. When SHBG was examined without sex discrimination, it was $74.07 \pm 25.48 \mathrm{ng} / \mathrm{dL}(13.00$ $144.80 \mathrm{ng} / \mathrm{dL})$.

FAl was $0.44 \pm 0.33(0.03-1.38)$ in girls and $1.42 \pm 0.54$ (0.69-3.46) in boys. FAl was $0.91 \pm 0.66(0.03-3.46)$ without sex discrimination.

The SHBG and FAI values are shown as mean, standard deviation, minimum, maximum, and 5th, 10th, 25th, 50th, 75th, 90th, and 95th percentiles in Table 1. 
Table 1

SHBG and FAI values and percentiles

\begin{tabular}{|c|c|c|c|c|c|c|c|}
\hline & & \multicolumn{3}{|c|}{ SHBG (ng/dL) } & \multicolumn{3}{|l|}{ FAl } \\
\hline & & Girl & Boy & Total & Girl & Boy & Total \\
\hline$n$ & & 40 & 36 & 76 & 40 & 36 & 76 \\
\hline Mean & & 74.84 & 73.22 & 74.07 & 0.44 & 1.42 & 0.91 \\
\hline Standard Deviation & & 26.21 & 24.98 & 25.48 & 0.33 & 0.54 & 0.66 \\
\hline Minimum & & 26.80 & 13.00 & 13.00 & 0.03 & 0.69 & 0.03 \\
\hline Maximum & & 135.20 & 144.80 & 144.80 & 1.38 & 3.46 & 3.46 \\
\hline \multirow[t]{8}{*}{ Percentile } & $\%$ & \multicolumn{3}{|c|}{ SHBG (ng/dL) } & \multicolumn{3}{|l|}{ FAl } \\
\hline & 5 & 34.35 & 33.49 & 36.65 & 0.13 & 0.69 & 0.16 \\
\hline & 10 & 44.35 & 41.53 & 43.75 & 0.16 & 0.89 & 0.18 \\
\hline & 25 & 52.67 & 58.13 & 55.50 & 0.19 & 1.06 & 0.28 \\
\hline & 50 & 71.95 & 74.30 & 73.40 & 0.30 & 1.31 & 0.91 \\
\hline & 75 & 90.97 & 84.25 & 88.12 & 0.64 & 1.70 & 1.32 \\
\hline & 90 & 114.40 & 101.70 & 109.32 & 1.01 & 2.12 & 1.76 \\
\hline & 95 & 123.30 & 131.11 & 124.28 & 1.16 & 2.53 & 2.09 \\
\hline
\end{tabular}

\section{Discussion}

Breast enlargement is not at the same pace for everyone. Even in normal puberty, the breast enlargement may be unilateral in some cases, and the other breast can catch up in about 6 months. Although hormone levels are the same in boys and girls, both breasts can have different sizes. This can be related to receptor insensitivity/hypersensitivity of breast tissues to estrogen and/or prolactin ${ }^{7}$. These conditions may explain the absence of breast enlargement in all newborns. Prolactin and estrogen are the major hormones in breast enlargement. Decreased maternal estrogen and increased prolactin have been shown in breast enlargement. There are several hypotheses proposed for neonatal breast enlargement. First, high concentrations of estrogen crossing the fetoplacental barrier cause growth and proliferation of the neonatal breast tissue. Second, it is assumed that the acute drop in estrogen levels after delivery stimulates the neonatal pituitary gland, causing hyperprolactinemia ${ }^{4}$. In recent publications in adults, estrogen, testosterone, SHBG, luteinizing hormone, follicular stimulating hormone, thyroid-stimulating hormone, prolactin, alpha-fetoprotein, human chorionic gonadotropin, liver, and renal function tests reported to be related to gynecomastia ${ }^{1}$. 
Various studies on the SHBG levels of children have been conducted, but no studies analyzed the plasma SHBG levels of newborns with breast enlargement. SHBG levels were high in premature telarche girls ${ }^{8}$. SHBG levels and FAI are more sensitive markers both in the etiology of gynecomastia and in the onset of puberty in boys ${ }^{9,10}$. In a study of pubertal gynecomastia, chronological age, height, BMI, serum estradiol, testosterone, and SHBG levels did not significantly differ between the pubertal gynecomastia group and the control group ${ }^{10}$.

One study found that the gynecomastia group had lower testosterone levels and higher BMI, but these differences between gynecomastia and control groups were not statistically significant ${ }^{11}$.

In a study of 536 adolescents with gynecomastia, comparison with the control/test groups revealed no difference in serum estradiol, testosterone levels, E/T ratio, and estrogen/DHEAS ratio. However, lower free testosterone levels, weight, BMI, and higher SHBG levels were observed in gynecomastia patients ${ }^{12}$.

In our study, estrogen levels, testosterone levels, and SGBH levels were lower in the test group. Additionally, FAl levels, E/T ratio, and BMI were high. However, chronological age, sex, weight, height, BMI, estrogen, testosterone, SHBG, FAl, and E/T ratio levels were not statistically significant in newborn breast enlargements. In our study, there was no significant difference in the SHBG levels of the study and control groups. This result shows similarities with the results found in adults with gynecomastia and premature telarche patients.

It is known that increased free testosterone and FAl levels reduce the risk of gynecomastia ${ }^{10,13}$. In our study, FAl levels were higher in the breast enlargement group. However, no significant differences in FAI levels were determined between the study and the control groups.

There are differences in the levels of the SHBG concentration in the blood circulation concerning sex, and SHBG levels of females are generally higher than males. In healthy children, SHBG was significantly negatively correlated with testosterone, estradiol, dehydroepiandrosterone sulfate, and BMI in boys. However, only dehydroepiandrosterone sulfate and BMI were negatively correlated in girls ${ }^{14}$.

In our study, no significant relationship was found between sex and estrogen and SHBG. However, a significant relationship was found between sex and testosterone, FAl, and E/T ratio. As a result, no significant relationship was found between sex and breast enlargement. There is no difference between boys and girls. Neonatal breast enlargement is independent of sex.

Neonatal breast enlargement is independent of weight, height, body mass index, estrogen, testosterone, SHBG, FAl, and E/T ratio.

The number of studies on neonatal breast enlargement is very limited. We have done a similar study previously ${ }^{15}$. In our previous study, Kisspeptin, follicle-stimulating hormone, luteinizing hormone, estradiol, and prolactin were studied. Kisspeptin, prolactin, and luteinizing hormone were significant but estradiol and follicle-stimulating hormone were not significant in this study 15 . 
Although estradiol is an effective hormone in normal pubertal telarche, it is ineffective in neonatal breast enlargement.

The reasons for this can be explained as follows:

a- neonatal ovaries have different estrogen secretion

b- due to the decline of maternal estradiol after birth, the real-time estradiol level in the blood is not the same

c-despite decreased estradiol, the reduction in breast tissue that could not catch decreased estradiol levels

d-the real-time estriol and estrone levels in the blood cannot be known

This is related to the fetus getting exposed to high concentrations of estrogen, primarily estriol, produced by the mother and the placenta ${ }^{4}$.

In our study, we have studied the effects of estradiol, not estriol and estrone combined. We could not find the effect of estradiol alone on breast enlargements in newborns. This situation can be explained by the effect of estriol and mammotropic peptides crossing the placenta that newborns' breasts enlarged beforehand. This study revealed the importance of other types of estrogen detection in neonatal breast enlargement.

Another aim of our study was to define the normals and percentiles of SHBG and FAI in newborn babies according to sex. According to our knowledge, SHBG normal and FAI normal have been defined in only one study in newborn infants ${ }^{16}$. In this study, SHBG was defined as nmol/L in infants aged 1-7 days, 714 days, and 14 days-3 months. Whereas, in our study, we determined the SHBG values as $\mathrm{ng} / \mathrm{dL}$ in 14-28 days newborns. We determined percentiles of SHBG and FAl normals. SHBG was $74.84 \pm 26.21 \mathrm{ng} / \mathrm{dL}$ $(26.80-135.20 \mathrm{ng} / \mathrm{dL})$ in girls and $73.22 \pm 24.98 \mathrm{ng} / \mathrm{dL}(13.00-144.80 \mathrm{ng} / \mathrm{dL})$ in boys. SHBG was $74.07 \pm 25.48 \mathrm{ng} / \mathrm{dL}(13.00-144.80 \mathrm{ng} / \mathrm{dL})$ without sex discrimination. FAl was $0.44 \pm 0.33(0.03-1.38)$ in girls and $1.42 \pm 0.54(0.69-3.46)$ in boys. FAl was $0.91 \pm 0.66(0.03-3.46)$ without sex discrimination.

The strengths of our study are that it is a rare study performed where the SHBG and FAI normals and percentile values of 14-28 days old newborns are examined.

The limitations of the study are determining estradiol only and the relatively low number of cases. Also, follicle stimulating hormone, luteinizing hormone, and prolactin were not studied because they were investigated in our previous study ${ }^{15}$.

\section{Conclusion}


In our study, normal values and 5th, 10th, 25th, 50th, 75th, 90th, and 95th percentiles of SHBG and FAI were defined according to sex. It was concluded that neonatal breast enlargement is independent of weight, height, body mass index, estrogen, testosterone, SHBG, FAI, E/T ratio, and especially sex. Our study has provided new information about newborn breast enlargements. In the physiology of neonatal breast enlargement, there are still situations that await clarification. Our study has revealed the need for large controlled studies on the physiology of breast enlargement in newborns.

\section{Abbreviations}

Sex Hormone Binding Globulin (SHBG), free androgenic index (FAl), Body Mass Index $(B M I)$, Estrogen/Testosterone ratio $(E / T)$

\section{Declarations}

Funding: No funding was secured for this study.

Conflict of Interest: The authors have no conflicts of interest to disclose.

Availability of data and material: Not applicable

Code availability: Not applicable

Authors' contributions: Dr.Avni Kaya, manuscript preparation, wiriting, patients doctor, data acquisition, literature research, Dr.Abdullah Erdil, manuscript preparation, wiriting, data acquisition, literature research, patients doctor, data acquisition. Prof.Dr.Zerrin Orbak, Consept, manuscript preparation, patient's doctor, manuscript reviewed

Ethics approval: Atatürk University, Faculty of Medicine, Ethical Committee. Session 7, Decision number: 62

Consent to participate: Not applicable

Consent for publication: Yes

\section{References}

1. Kanakis GA, Nordkap L, Bang AK, Calogero AE, Bartfai G, Corona G et al (2019) EAA clinical practice guidelines-gynecomastia evaluation and management. Andrology-Us 7(6):778-793

2. Narula HS, Carlson HE (2014) Gynaecomastia-pathophysiology, diagnosis and treatment. Nat Rev Endocrinol 10(11):684-698

3. Jayasinghe Y, Cha R, Horn-Ommen J, O'Brien P, Simmons PS (2010) Establishment of Normative Data for the Amount of Breast Tissue Present in Healthy Children up to Two Years of Age. J Pediatr Adol Gynec 23(5):305-311 
4. Diamantopoulos S, Bao Y (2007) Gynecomastia and premature thelarche: A guide for practitioners. Pediatr Rev 28(9):E57-E68

5. Selby C (1990) Sex-Hormone Binding Globulin - Origin, Function and Clinical-Significance. Ann Clin Biochem 27:532-541

6. Ibanez L, Potau N, Marcos MV, de Zegher F (2000) Treatment of hirsutism, hyperandrogenism, oligomenorrhea, dyslipidemia, and hyperinsulinism in nonobese, adolescent girls: Effect of flutamide. J Clin Endocr Metab 85(9):3251-3255

7. Öcal; G, Şıklar Z (2014) Puberte Fizyolojisi. Peyami Cinaz FD, Ayşehan Akıncı, Behzat Özkan, Bumin N. Dündar, Ayhan Abacı, Teoman Akçay., editor. Temel Çocuk Endokrinoloji. Nobel Tıp Kitabevleri, İstanbul, pp 153-164

8. Belgorosky A, Chaler E, Rivarola MA (1992) High Serum Sex Hormone-Binding Globulin (Shbg) in Premature Thelarche. Clin Endocrinol 37(3):203-206

9. Kim MR, Gupta MK, Travers SH, Rogers DG, Van Lente F, Faiman C (1999) Serum prostate specific antigen, sex hormone binding globulin and free androgen index as markers of pubertal development in boys. Clin Endocrinol 50(2):203-210

10. Kilic M, Kanbur N, Derman O, Akgul S, Kutluk T (2011) The relationship between pubertal gynecomastia, prostate specific antigen, free androgen index, SHBG and sex steroids. J Pediatr Endocr Met 24(1-2):61-67

11. Ersoz HO, Onde ME, Terekeci $H$, Kurtoglu S, Tor $H$ (2002) Causes of gynaecomastia in young adult males and factors associated with idiopathic gynaecomastia. Int J Androl 25(5):312-316

12. Biro FM, Lucky AW, Huster GA, Morrison JA (1990) Hormonal Studies and Physical Maturation in Adolescent Gynecomastia. J Pediatr-Us 116(3):450-455

13. Elmlinger MW, Kuhnel W, Wormstall H, Doller PC (2005) Reference intervals for testosterone, androstenedione and SHBG levels in healthy females and males from birth until old age. Clin Lab 51(11-12):625-632

14. Sorensen K, Andersson AM, Skakkebaek NE, Juul A (2007) Serum sex hormone-binding globulin levels in healthy children and girls with precocious puberty before and during gonadotropin-releasing hormone agonist treatment. J Clin Endocr Metab 92(8):3189-3196

15. Kaya A, Orbak Z, Polat H, Cayir A, Erdil A, Doneray H (2015) Plasma Kisspeptin Levels in Newborn Infants with Breast Enlargement. J Clin Res Pediatr E 7(3):192-196

16. Elmlinger MW, Kuhnel W, Ranke MB (2002) Reference Ranges for Serum Concentrations of Lutropin (LH), Follitropin (FSH), Estradiol (E2), Prolactin, Progesterone, Sex Hormone-Binding Globulin (SHBG), Dehydroepiandrosterone Sulfate (DHEAS), Cortisol and Ferritin in Neonates, Children and Young Adults. Clin Chem Lab Med 40(11):1151-1160 